\title{
Carcinoma de células de Merkel
}

\section{Merkel cell carcinoma}

\author{
Andrea Soledad Rama ${ }^{1}$, Vicenta Neglia² y Alejandra Abeldaño ${ }^{3}$
}

\section{RESUMEN}

El carcinoma de células de Merkel (CCM) cutáneo es una neoplasia de curso agresivo, con tasas de mortalidad mayores que las del melanoma y un alto índice de recurrencia locorregional y de metástasis a distancia. Su incidencia es baja, pero en los últimos años se encuentra en aumento y se estima que continuará en ascenso.

Afecta con mayor frecuencia a pacientes añosos, en especial mayores de 65 años, con un ligero predominio en los varones. Su etiopatogenia está relacionada, por un lado, con la exposición a la radiación ultravioleta (RUV) y, por el otro, con la infección por un nuevo poliomavirus (MCPyV), el primero asociado a neoplasias en los seres humanos.

Suele aparecer como una lesión tumoral eritematosa, de consistencia firme y rápido crecimiento, asintomática, en áreas fotoexpuestas de la piel. Debido a que no presenta un rasgo distintivo, su sospecha clínica es baja y, en general, puede confundirse con lesiones benignas.
El diagnóstico se realiza mediante la clínica y el estudio histopatológico e inmunohistoquímico (IHQ) de la lesión. Con tinción de hematoxilina y eosina se observa un tumor compuesto por células basófilas pequeñas, de citoplasma escaso y con núcleos hipercromáticos. La IHQ presenta marcación positiva para la citoqueratina 20 , con una elevada sensibilidad. La extirpación quirúrgica de la lesión primaria es el tratamiento de elección. Las últimas recomendaciones incluyen el estudio histopatológico del ganglio centinela ante el diagnóstico de CCM para obtener una correcta estadificación. De acuerdo con el estadio, se procederá al abordaje terapéutico de forma interdisciplinaria.

Palabras clave: carcinoma de células de Merkel, poliomavirus.

Dermatol. Argent. 2020, 26 (4): 140-152

\section{ABSTRACT}

Merkel cell carcinoma (MCC) is an aggressive skin tumor, with higher mortality rates than melanoma, and high rates of locoregional recurrence and distant metastases. Its incidence is low but it has been increasing in the last years, and it is estimated that it will continue to rise.

It more frequently affects elderly patients, especially those over 65 years old, with a slight predominance in men. Its etiopathogenesis is related, on the one hand, to ultraviolet radiation exposure (UVR), and on the other, with the infection of a new polyomavirus, the first one associated with neoplasias in humans.

Usually it presents as an erythematous, firm, fast growing and asymptomatic tumor, in sun-exposed areas of the skin. Because it lacks distinguishing characteristic features, its clinical suspicion is low and generally can be confused with benign lesions.
The diagnosis is made through the clinical, histopathological and immunohistochemical study of the lesion. With hematoxylin and eosin staining, we can observe it is composed of small blue cells, with sparse cytoplasm and hyperchromatic nuclei. Immunohistochemistry is positive for cytokeratin 20 with high sensitivity.

Surgical removal of the primary tumor constitutes the preferred treatment. The latest recommendations include the histopathological study of the sentinel node when MCC is diagnosed for a correct staging. According to the stage, the therapeutic approach will planned in a multidisciplinary way.

Key words: Merkel cell carcinoma, polyomavirus.

Dermatol. Argent. 2020, 26 (4): 140-152
${ }^{1}$ Médica Concurrente de Quinto Año

${ }^{2}$ Médica de Planta

3 Jefa de la Unidad

Unidad de Dermatología, Hospital General de Agudos

Dr. Cosme Argerich, Ciudad Autónoma de Buenos Aires, Argentina
Contacto del autor: Andrea Soledad Rama

E-mail: ramasoledad@gmail.com

Fecha de trabajo recibido: $7 / 7 / 2020$

Fecha de trabajo aceptado: 9/12/2020

Conflicto de interés: las autoras declaran que no existe conflicto de interés. 


\section{RESEÑA HISTÓRICA}

En 1972, Toker describió por primera vez el carcinoma que hoy se conoce como de células de Merkel y lo denominó carcinoma de células trabeculares de la piel debido a su patrón histológico. En esa publicación, donde presentaba 5 casos y describía los hallazgos histológicos, aseguró que se trataba de una nueva entidad maligna con un origen celular incierto. Al principio propuso un posible origen carcinoide, pero lo descartó al no hallar gránulos. Debido a la disposición histoarquitectural trabecular sin acinos, planteó entonces un posible origen a partir de células inmaduras epiteliales, capaces de reproducir estructuras sudoríparas rudimentarias ${ }^{1}$. En 1978, Tang y Toker lograron identificar, mediante microscopia electrónica, gránulos densos en el citoplasma de estas células tumorales y relacionaron su origen con la célula de Merkel, dado el componente neuroendocrino ${ }^{2}$.

Sinonimia: carcinoma trabecular, apudoma cutáneo, carcinoma neuroendocrino primario cutáneo, carcinoma de células pequeñas primario cutáneo, carcinoma indiferenciado primario cutáneo y merkeloma.

\section{EPIDEMIOLOGÍA}

Se estima que dos tercios de todos los CCM afectan a los varones. En todos los grupos etarios, la incidencia es mayor en los hombres y es aún más pronunciada en los adultos mayores. La tasa de incidencia ajustada a la edad aumenta a partir de los 65 ańos y es la más alta en los mayores de 85 años (4,28/100.000 habitantes) (Gráfico 1). La media de edad en el momento del diagnóstico es entre los 75 y los 79 años. El 95\% de los pacientes son caucásicos ${ }^{3-8}$.

Acorde con los datos publicados, si bien su incidencia actual es baja en comparación con otros tumores cutáneos, en los últimos años se observó que se encuentra en aumento y, a partir de ello, algunos autores proyectan una curva que continuaría en ascenso ${ }^{3}$. En Estados Unidos, entre 1986 y 2001, según la base de datos del Surveillance, Epidemiology, and End Results (SEER) Program, la incidencia se triplicó y la tasa ajustada a la edad aumentó de 0,15 a 0,44 por 100.000 habitantes. Esto representa un incremento de la incidencia del $8 \%$ anual, en comparación con la del melanoma, que fue del $3 \%{ }^{5}$. En 2004, el número de casos por año de CCM fue de 986, en 2007 aumentó a 1.500 casos y superó al linfoma de células $\mathrm{T}$ (Gráfico 2) ${ }^{9}$. La incidencia continuó en aumento de forma constante desde 1986 y en 2013 fue de 0,7 por 100.000 habitantes, con 2.488 de casos al año. De acuerdo con esta tendencia, se estima que el número podría crecer a 2.835 casos en 2020 y a 3.284 casos en $2025^{3}$. El aumento de la incidencia en los últimos años también se observó en otros países como Australia, Suiza, Francia, Alemania, Holanda y Dinamarca ${ }^{6,8,10-14}$. No obstante, la incidencia global es muy difícil de estimar debido a lo infrecuente de la patología.

El incremento de los casos registrados se debe, por un lado, a la implementación de técnicas de inmunohistoquímica que permitieron un mayor diagnóstico. Antes había un subdiagnóstico de esta entidad y este mejoró significativamente a partir de la década de 1990 con la marcación de la citoqueratina 20 (CK20) en las muestras de biopsia ${ }^{3}$. Existe un aumento real de casos, ya que su incidencia es notablemente mayor en la población añosa. Cabe destacar que en los países en los que se llevan a cabo los grandes estudios
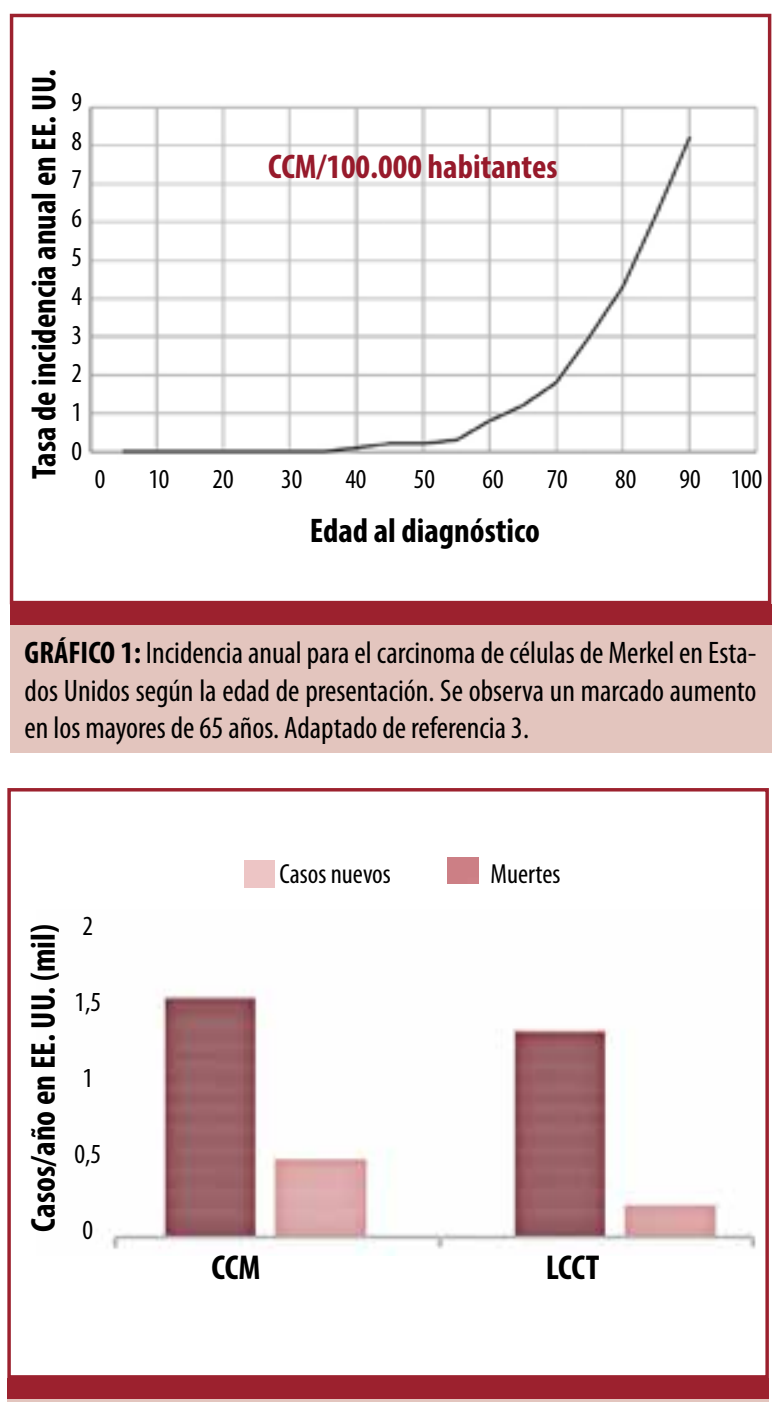

GRÁFICO 2: Incidencia anual y mortalidad en Estados Unidos. Se observa que la incidencia y la mortalidad del carcinoma de células de Merkel superan ligeramente a los de los linfomas cutáneos de células T (LCCT). Datos de American Cancer Society, 2006; Weinstock and Gardstein, 1999. Adaptado de referencia 3. 
epidemiológicos de referencia, hay un incremento en el número de individuos de este grupo etario debido al envejecimiento de la generación de los baby-boomers, individuos nacidos entre 1935 y 1960, que tienen una historia de intensa fotoexposición ${ }^{3-9}$. Además, la identificación de poblaciones de riesgo aumentó la sospecha de esta entidad y se estima que ha habido un incremento de la comunicación sobre ella ${ }^{5,7}$.

\section{FACTORES DE RIESGO}

Se reconocen como principales factores de riesgo: la exposición a RUV, la edad avanzada y los estados de inmunosupresión severa. La exposición a la RUV es uno de los más importantes, ya que hasta un $81 \%$ de los tumores se encuentran en áreas fotoexpuestas de la piel, principalmente la cabeza y el cuello. Sin embargo, hay casos de CCM en áreas no fotoexpuestas como los glúteos $(5 \%)^{15}$. En las regiones geográficas con altos índices de RUV, como Australia y Nueva Zelanda, se presentan las mayores tasas de incidencia ${ }^{4,10}$. En Queensland, Australia, donde se registraron las tasas más altas para cáncer de piel, en especial el melanoma invasor, Youlden et ál. analizaron 879 casos de CCM diagnosticados entre 1993 y 2010. La incidencia fue de 1,6 cada 100.000 habitantes, el doble con respecto al resto del mundo ${ }^{6}$.

Mediante el estudio genético del ADN de las células tumorales, se observó el daño inducido por la RUV, con mutaciones similares a las halladas en otros carcinomas relacionados con la fotoexposición ${ }^{16}$. Estos pacientes tendrían mayor riesgo de padecer carcinoma espinocelular (CEC) y melanoma ${ }^{8}$. Es posible encontrar CEC (algunos autores señalan hasta un $40 \%$ de asociación) y, con menor frecuencia, carcinoma basocelular (CBC) y melanoma en la misma lesión tumoral o adyacente a esta ${ }^{17,18}$. En una publicación en la que se estudiaron de forma prospectiva 1.380 pacientes con psoriasis y tratamiento con fototerapia (UVA + psoralenos) con el objetivo de conocer los riesgos a largo plazo de la exposición a la radiación UVA, se observó una incidencia 100 veces mayor de CCM con respecto a la población general ${ }^{19}$.

Como ya se dijo, la prevalencia aumenta significativamente con la edad, lo cual habla de un mayor riesgo de padecer este tumor en las personas de edad avanzada. Por otro lado, los pacientes inmunosuprimidos severos, con una respuesta inmune celular deficiente, como los oncohematológicos, los trasplantados de órganos sólidos y los infectados por el virus de la inmunodeficiencia humana (HIV), también presentan un aumento del riesgo ${ }^{8,15,20}$. Algunos estudios resaltan que estos pacientes tenían, en el momento del diagnóstico, una enfermedad localmente avanzada, metástasis ganglionares o a distancia, con mayor frecuencia que aquellos inmunocompetentes. Debido a la considerable asociación de esta neoplasia con los estados de inmunosupresión, se destaca la necesidad de estudiar el estado inmunitario del paciente frente al diagnóstico de $\mathrm{CCM}^{15}$.

\section{ETIOPATOGENIA}

La asociación entre el CCM y los estados de inmunosupresión severa, como sucede con el sarcoma de Kaposi, una neoplasia inmunorrelacionada asociada al herpesvirus humano 8 (HHV 8), fue un disparador para la investigación de un posible origen infeccioso. En 2008, Feng et ál. publicaron un estudio en el cual, mediante la secuenciación de ARN tumoral de muestras de CCM, aislaron un nuevo poliomavirus ${ }^{21}$. Hasta el momento se conocían cuatro: el BKV, agente causal de la nefropatía y la pérdida del órgano en los trasplantados renales; el JCV, responsable de la leucoencefalopatía multifocal progresiva en los pacientes con HIV, y el WUPyV y el KIPyV, hallados en el tracto respiratorio, sin patología asociada. El quinto, llamado poliomavirus de células de Merkel (MCPyV: Merkel cell polyoma virus), se halló en el $80 \%$ de las muestras estudiadas y se denominó a estos tumores $\mathrm{MCPyV}$-positivos. Este porcentaje se confirmó en un estudio en el que se recopilaron 819 muestras tumorales de CCM de 27 estudios de distintas partes del mundo. Cabe destacar que se ha detectado ADN de MCPyV en muestras de piel de personas sanas ${ }^{22}$.

El potencial oncogénico viral estaría relacionado con los antígenos T, large T antigen (LTag) y small T antigen $(s \mathrm{~T})$, considerados genes tempranos por su rápida expresión tras la infección. La integración de MCPyV al genoma de la célula huésped no parece ocurrir en ningún "punto caliente" responsable de la activación o inactivación de genes, sino que al integrarse al genoma viral produciría mutaciones o deleciones que darían como resultado el truncamiento de la porción C-terminal de LTag. Así, se facilitaría el desarrollo tumoral y la producción de viriones y se evitaría la estimulación de la respuesta inmunitaria citotóxica. Respecto del antígeno sT, los estudios experimentales demostraron que ambos antígenos son necesarios para el mantenimiento de las células tumorales, lo cual las convierte en posibles blancos terapéuticos. La integración del virus al genoma celular se produce antes de la expansión clonal neoplásica, pero por sí sola no sería suficiente para el desarrollo del tumor y la mutación genómica sería una condición necesaria ${ }^{21-23}$. Algunos autores sostienen que los estados de inmunosupresión facilitan la integración de $\mathrm{MCPyV}$ al genoma celular, como también la proliferación de las células malignas ${ }^{21}$. 
Por otro lado, existen los tumores MCPyV-negativos que, en contraposición con los MCPyV-positivos, presentan una alta carga de mutaciones en estrecha relación con las producidas por la RUV (mayor fracción de citidina sobre timina y abundantes dímeros de pirimidinas), con un genoma inestable. La mayoría de estos de tumores suelen desarrollarse en zonas fotoexpuestas de la piel y son más frecuentes en las regiones geográficas con altos índices de radiación $\mathrm{UV}^{16,24}$. Los genes mutados son P53, RB1, NOTCH 1-4 y PRU$N E 2$ (genes supresores de tumores) y las vías oncogénicas alteradas PI3K con mayor frecuencia, KNSTRN, RAC1 y HRAS ${ }^{24}$.

A partir del hecho de que los tumores que contienen una alta carga mutacional en su ADN suelen presentar una respuesta inmune elevada y una respuesta sostenida a las terapias biológicas con inhibidores de los puntos de control inmunitarios, Wong et ál. estudiaron lo que sucedía en el CCM con el infiltrado inflamatorio linfocitario y la presencia de PD-L1 ligando en muestras tumorales como indicadores de control inmunitario. Los tumores MCPyV-positivos mostraron un importante infiltrado linfocitario y niveles de PD-L1 elevados. Los tumores MCPyV-negativos presentaron grados variables de infiltrado linfocitario y PD-L1 pero, llamativamente, altos en los tumores con alta carga mutacional ${ }^{16}$. Estos hallazgos respaldan el concepto de que el CCM, cualquiera que sea su etiología, es una neoplasia inmunorrelacionada.

\section{CLÍNICA}

El CCM es una neoplasia infrecuente, sin características clínicas distintivas, con baja sospecha clínica, por lo que suele demorarse en el diagnóstico. Este es un aspecto clave, ya que el diagnóstico precoz en estadios tempranos modifica drásticamente el pronóstico del paciente.

Con el propósito de mejorar la sospecha clínica, Heath $e t a ́$ al. publicaron un estudio en el que describen con minuciosidad las características clínicas de 195 pacientes con CCM. El tumor se presentó como una masa sólida eritematosa $(56 \%)$ o azul/violácea $(26 \%)$, asintomática (88\%) y firme, de rápido crecimiento, localizada en áreas fotoexpuestas (cabeza y cuello $29 \%$, miembros inferiores $24 \%$ y miembros superiores $21 \%$, las más frecuentes), aunque un $19 \%$ se encontró en áreas protegidas del sol. Estas características se resumieron con el acrónimo AEIOU (Tabla 1) y el 89\% de los CCM reunieron al menos tres de ellas. Entre los diagnósticos diferenciales planteados antes de arribar al diagnóstico definitivo, más de la mitad correspondieron a lesiones benignas y solo el $1 \%$ pensó en el CCM. Una lesión quística o acneiforme fue el diag- nóstico presuntivo más frecuente (32\%), seguido del cáncer no melanoma $(19 \%)^{15}$. En la literatura médica nacional, las descripciones clínicas en general coinciden y se presenta como una lesión tumoral eritematosa o eritematoviolácea, hemisférica o nodular, de superficie lisa y rápido crecimiento, en ocasiones ulcerada y costrosa (Fotos 1 y 2$)^{25-30}$.

\section{Características dínicas del carcinoma de células de Merkel}

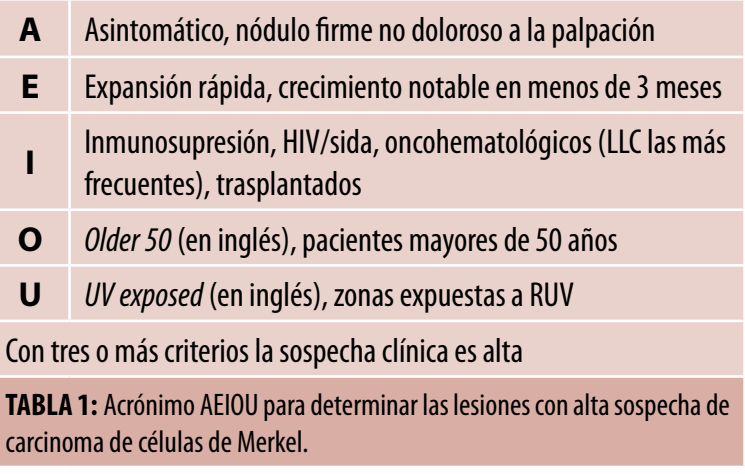

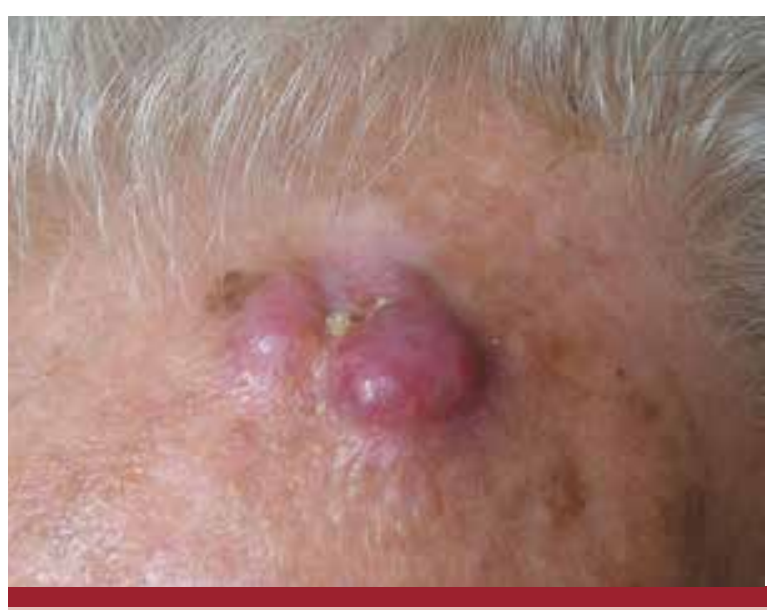

FOTO 1: Lesión tumoral eritematosa lobulada, de superficie lisa y brillante y centro deprimido con escasa costra queratósica, dura a la palpación de 4 $\mathrm{cm}$ de diámetro.

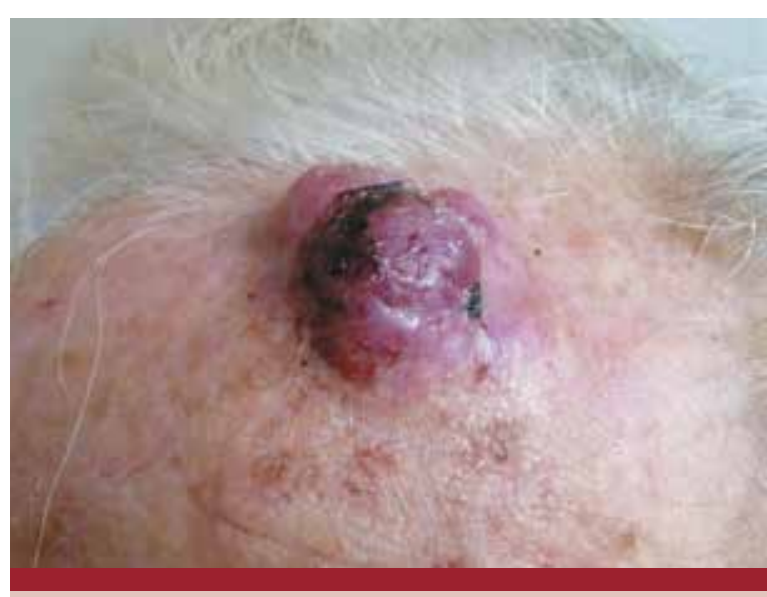

FOTO 2: Misma lesión tumoral al control al mes aumentada de tamaño, exofítica, con abundante costra hemática en su superficie. 


\section{DIAGNÓSTICO}

Para arribar al diagnóstico es fundamental el estudio histopatológico e inmunohistoquímico, en lo posible efectuado por un dermatopatólogo con experiencia en el tema.

El estudio histológico con hematoxilina y eosina revela un tumor compuesto por células basófilas pequeñas y monomorfas localizadas en la dermis, que puede extenderse hasta la hipodermis y disponerse en varios patrones: en cordones, trabecular, organoide, difuso o mixto (Foto 3) ${ }^{17,31}$. Por lo general, respeta la epidermis y los anexos, pero con escasa frecuencia puede observarse epidermotropismo y hasta un componente epidérmico extenso. En cuanto a la citología, se trata de células ovoides pequeńas que tienen escaso citoplasma, núcleos hipercromáticos, con cromatina finamente granular, con aspecto de sal y pimienta, y un nucléolo pequeño o ausente. Son frecuentes las figuras mitóticas y apoptóticas y, en los tumores de gran tamaño, puede observarse necrosis (Foto 4$)^{31,32}$.

Es posible encontrarlo en combinación con otras neoplasias o adyacente a estas, como el CEC (el más frecuente), el CBC, los tumores anexiales y los sarcomas. La frecuencia con la que se halló combinado es muy variada. En un estudio en el que se analizaron 27 carcinomas de Merkel, un $40 \%$ se encontraban combinados con lesiones epiteliales adyacentes o en la misma lesión (CEC, queratosis actínicas y $\mathrm{CBC}$, en orden de frecuencia $)^{18}$. Algunos autores señalan que si bien podría tratarse de un tumor de colisión, debido a la interrelación entre las células neuroendocrinas con las escamosas, es posible que se trate de tumores bifenotípicos (convergentes) CEC + $\mathrm{CCM}^{32}$.

Los diagnósticos diferenciales que se plantean desde el punto de vista histopatológico incluyen otros tumores de células basófilas pequeñas, como metástasis de carcinoma de células pequeñas de pulmón, carcinoide metastásico, linfomas, melanoma, CBC, sarcoma de Ewing, neuroblastoma, carcinoma ecrino pobremente diferenciado, carcinoma escamoso y rabdomiosarcoma. En caso de haber epidermotropismo, debe diferenciarse de la enfermedad de Paget, la enfermedad de Bowen, los linfomas T, el melanoma y el carcinoma sebáceo ${ }^{17,31,32}$.

La IHQ mejora la certeza diagnóstica de una lesión con clínica e histología compatibles y ayuda al diagnóstico diferencial. El CCM expresa marcadores epiteliales (CAM 5.2, AE1/AE3, CK20 y EMA), neuroendocrinos (cromogranina, sinaptofisina, enolasa neuroespecífica) y neuronales (NCAM y CD56). La mayoría son positivos para la citoqueratina 20 (CK20), con un patrón en punto paranuclear característico resultante de la aglomeración de filamentos intermedios, pero pueden también tener un patrón citoplasmático difuso o membranoso (Foto 5) ${ }^{31,32}$. En un estudio de

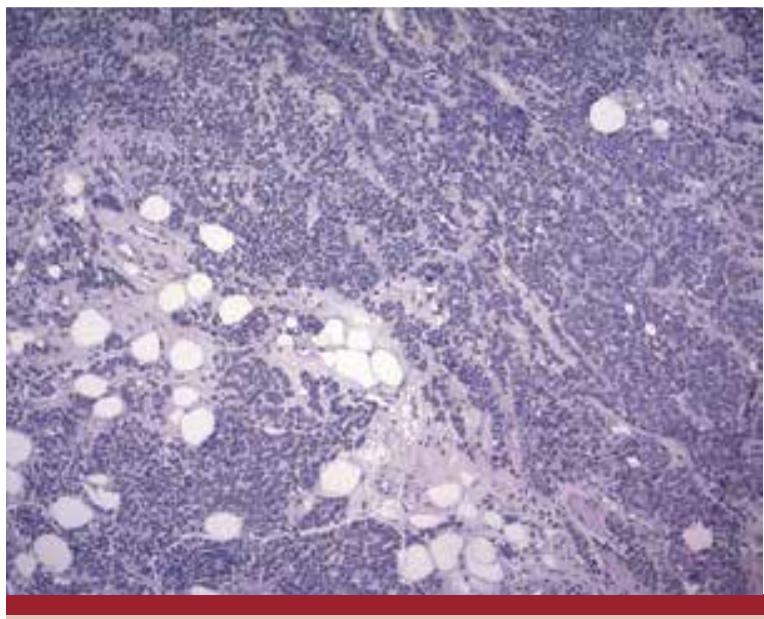

FOTO 3: Proliferación dérmica atípica compuesta por células pequeñas y redondas dispuestas en grandes grupos y en hileras (HyE, 10X).

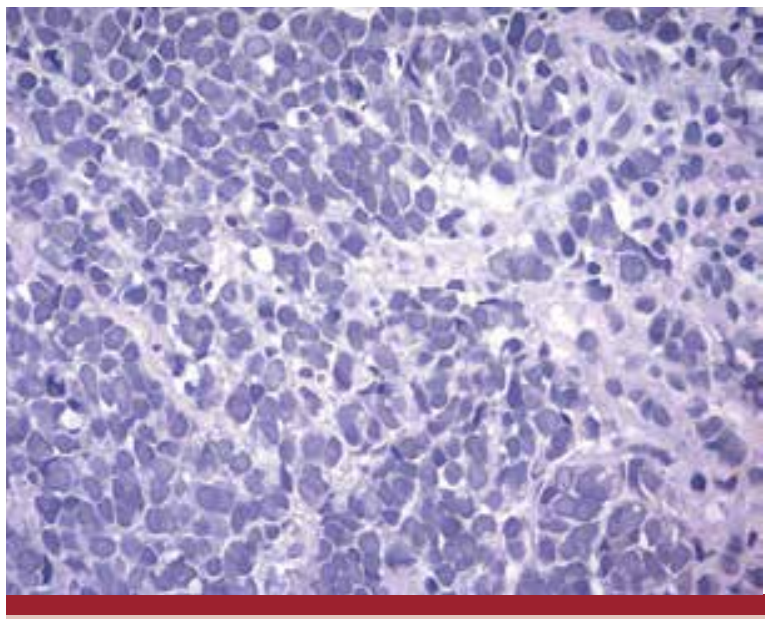

FOTO 4: Células redondas de escaso citoplasma, núcleos con cromatina granular en sal y pimienta, y abundantes mitosis (HyE, 40X).

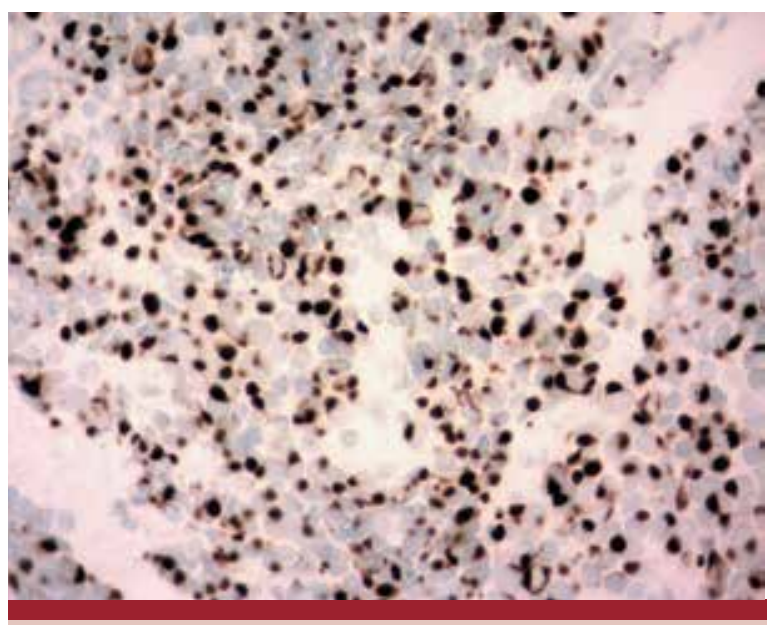

FOTO 5: Técnica de inmunomarcación. Se observa positividad citoplasmática para CK20 en forma de punto paranuclear (HyE, 40X). 
100 muestras, el 95\% presentó inmunomarcación positiva para neurofilamento en un patrón en punto paranuclear y se concluyó que podría ser una herramienta útil para el diagnóstico, pero subutilizada hasta ese momento ${ }^{33}$. Si bien el resto de los marcadores no son específicos, en conjunto son útiles ante la dificultad diagnóstica. Las metástasis de los carcinomas de células pequeñas de pulmón representan un desafío diagnóstico histopatológico. Son típicamente TTF-1 (Thyroid transcription factor-1) y citoqueratina 7 (CK7) positivas y CK20 negativas. Se destaca que excepcionalmente los CCM pueden marcar CK7 hasta en un 25\% y, en menor medida, el TTF-1(Tabla 2) $)^{31,32}$.

El American Joint Committee of Cancer (AJCC) insiste en la utilidad de implementar un protocolo de informe histopatológico con un formato sinóptico y que sea ampliamente difundido. Esto sería de valor no solo para la estadificación del tumor, sino para el análisis retrospectivo de los factores diagnósticos y pronósticos. El College of American Pathologists (CAP) elaboró uno en 2010, modificado en 2017, que incluye datos necesarios para la estadificación y con valor pronóstico: tamaño del tumor (diámetro), extensión extracutánea (fascia, músculo, cartílago, hueso), evaluación nodal y agrega otras características para evaluar su impacto en el pronóstico: sitio del tumor, compromiso de los márgenes periféricos y en profundidad, invasión linfovascular, espesor del tumor, índice mitótico, patrón de crecimiento tumoral, infiltrado linfocitario y segunda neoplasia maligna ${ }^{34}$.

\begin{tabular}{|c|c|c|c|c|}
\hline Marcador & CCM & CCPP & Linfoma & Melanoma \\
\hline CK20 & + & & & \\
\hline CK7 & & + & & \\
\hline NSE & + & $+1-$ & & \\
\hline $\mathrm{CgA}$ & $+/-$ & $+1-$ & & \\
\hline TTF-1 & & + & & \\
\hline LCA & & & + & \\
\hline $\begin{array}{l}\text { Melan-A y } \\
\text { HMB-45 }\end{array}$ & & & & + \\
\hline \multicolumn{5}{|c|}{ 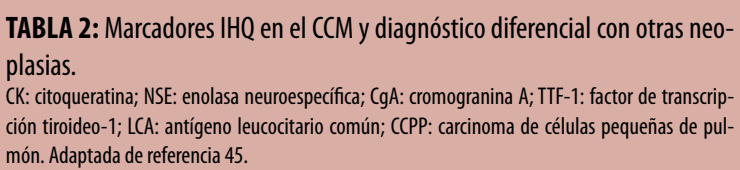 } \\
\hline
\end{tabular}

\section{ABORDAJE DEL PACIENTE CON SOSPECHA}

\section{DE CARCINOMA DE CÉLULAS DE MERKEL}

Ante la sospecha clínica de CCM es necesario realizar un examen físico completo de la piel con palpación de los ganglios linfáticos, seguido de la toma de biopsia cutánea para el estudio histopatológico e inmunohistoquímico y la confirmación diagnóstica.

El estudio por imágenes tendría por objetivo el hallazgo de posibles metástasis a distancia para una correcta estadificación aunque, según las distintas publicaciones, su utilidad es controvertida. En cuanto a la tomografía computada (TC), hay pocos estudios con muestras grandes. Uno de ellos $(n=122)$ mostró una baja sensibilidad, con un $80 \%$ de falsos negativos para la detección de metástasis ganglionares regionales (sin evidencia clínica de compromiso ganglionar y con confirmación histopatológica) y una alta sensibilidad, pero baja especificidad, para las metástasis a distancia ${ }^{35}$. Otro estudio con 99 pacientes halló una sensibilidad del 44\% para detectar metástasis ganglionares mediante la palpación en el examen físico, del $47 \%$ por TC, del $0 \%$ por resonancia magnética $(\mathrm{RM})$ y del $83 \%$ por tomografía por emisión de positrones (PET) ${ }^{36}$.

Según las recomendaciones de la guía de la National Comprehensive Cancer Network (NCCN) para el CCM de 2019, el estudio corporal total por imágenes con PET/TC multicorte o TC con contraste, con RM o no de cerebro, estaría indicado siempre en presencia de adenopatías regionales palpables con histopatología positiva, ganglio centinela positivo o en el estudio inicial del paciente con alta sospecha de metástasis según la clínica o los hallazgos histopatológicos del tumor primario. El método más confiable para el estudio de los ganglios subclínicos para obtener una correcta estatificación es la biopsia del ganglio centinela ${ }^{37}$.

La detección de anticuerpos para MCPyV podría contemplarse dentro de los estudios solicitados al inicio, dado que los pacientes seronegativos tendrían mayor riesgo de recurrencia y, en los seropositivos de inicio, un aumento del título de anticuerpos sería un marcador temprano de recaída ${ }^{37}$.

Es fundamental un enfoque multidisciplinario del paciente, en el que participen dermatólogo, médico clínico, especialista en diagnóstico por imágenes, dermatopatólogo, cirujano y oncólogo.

\section{ESTADIFICACIÓN}

La estadificación del paciente es menester para el correcto abordaje terapéutico y aporta información esencial respecto del pronóstico. En el pasado había cinco sistemas diferentes basados en los estudios de cohorte con muestras pequeñas (menores de 250 casos), en los 
que el estadio III representaba enfermedad local, nodal o metastásica, según qué sistema se utilizara, lo que creaba confusión y falta de consenso.

En 2010 se publicó el primer sistema de estadificación específico para CCM por el AJCC 7. a edición, basado en el análisis de $4.700 \operatorname{casos}^{38}$. Se definió el TNM y se establecieron los estadios (Tablas 3 y 4). Lo que destaca este sistema de los anteriores, además de consensuar criterios para estadificar el CCM, es que distingue el método por el cual se determina la presencia de metástasis a los ganglios regionales $(\mathrm{N})$. Se dividen en clínicas (c) o histológicas (p), según sean evidentes mediante inspección clínica y/o radiológica, o por el estudio histopatológico de linfadenectomía o ganglio centinela respectivamente ${ }^{38}$.

A continuación, se publicaron varios trabajos en los que se destacó la importancia del estudio del ganglio centinela para la estadificación, tras demostrar que el compromiso ganglionar es un factor pronóstico determinante (sobrevida a los 5 años de los pacientes con

\section{TNM}

\section{T: Tumor primario \\ Tx tumor primario desconocido \\ Tis in situ \\ T1 menor 0 igual a $2 \mathrm{~cm}$ de diámetro \\ T2 mayor de $2 \mathrm{~cm}$ y menor de $5 \mathrm{~cm}$ \\ T3 mayor de $5 \mathrm{~cm}$ \\ T4 con extensión a fascia, músculo, cartílago o hueso}

$\mathrm{N}$ : metástasis a ganglios regionales, definidas como el compromiso de una estación nodal o dos contiguas (p. ej., ilíaca/femoral o axilar bilateral en tumores del tronco)

Nx indeterminado

cNO clínicamente no evidentes (sin estudio histopatológico)

pNO estudio histopatológico negativo

N1 metástasis, N1a micrometástasis (células tumorales en estudio histopatológico sin adenopatías clínicas), N1b macrometástasis (adenopatía clínica confirmada por histopatología. En caso de no poder confirmarla, se la establece como N1b para estadificar),

N2 metástasis en tránsito (tumor nuevo entre el tumor primario y los ganglios regionales o distal a la lesión primaria)

M: metástasis a distancia, más allá de los ganglios regionales de drenaje, incluidos piel, ganglios y vísceras

MO sin metástasis a distancia

M1 metástasis a distancia M1a piel, tejido celular subcutáneo 0 ganglios a distancia, M1b pulmón, M1c cualquier otra víscera

TABLA 3: Estadificación del CCM según la 7. a edición del AJCC, 2010. ganglios negativos por estudio histopatológico del $76 \%$ contra el 59\% de los pacientes sin adenopatías clínicas evidentes). Hasta un tercio de los pacientes con micrometástasis y sin adenopatías clínicas hubieran estado mal estadificados y, por lo tanto, subtratados ${ }^{35,39-41}$.

La última actualización de la guía para el manejo del CCM de la NCCN de 2019 incluye la estadificación de la 8. ${ }^{a}$ edición de 2017 del AJCC basada en el estudio de 9.387 casos, con una media de seguimiento de 28,2 meses $^{42}$. En ella se menciona que según la estadificación anterior los pacientes con ganglios negativos por estudio histopatológico (IIA) tenían mejor pronóstico que aquellos sin compromiso ganglionar clínico evidente (IIB), probablemente porque dentro de este último grupo habría pacientes con micrometástasis no detectadas. Por este motivo, se establece el estudio del ganglio centinela con IHQ para estadificar correctamente a todo paciente pasible de tratamiento quirúrgico, sin evidencias de metástasis a distancia, para un mejor control de la enfermedad locorregional, a pesar de que su impacto en la sobrevida global es aún incierto. Difiere con respecto a la edición anterior en que distingue si la estadificación de $\mathrm{N}$ y el $\mathrm{M}$ es clínica o histopatológica; además, incluye un estadio aparte para los pacientes con enfermedad nodal y tumor primario desconocido, los cuales presentan mejor pronóstico con respecto a quienes padecen un tumor primario conocido y metástasis ganglionar (Tablas 5 y 6$)^{43}$.

Sobre la base de una correcta estadificación, la guía de la NCCN propone una serie de algoritmos para el manejo del paciente (Gráficos 3 a 6) ${ }^{37}$.

\begin{tabular}{|c|c|c|c|}
\hline Estadio & $T$ & N & M \\
\hline 0 & Tis & No & MO \\
\hline IA & $\mathrm{T} 1$ & pNO & MO \\
\hline IB & $\mathrm{T} 1$ & cNO & Mo \\
\hline$\| A$ & $\mathrm{~T} 2 / \mathrm{T} 3$ & pNO & MO \\
\hline$\| B$ & $\mathrm{~T} 2 / \mathrm{T} 3$ & cNO & Mo \\
\hline$\| C$ & T4 & No & Mo \\
\hline IIIA & Cualquier T & N1a & Mo \\
\hline IIIB & Cualquier T & $\mathrm{CN} 1 / \mathrm{N} 1 \mathrm{~b} / \mathrm{N} 2$ & MO \\
\hline IV & Cualquier T & Cualquier N & M1 \\
\hline \multicolumn{4}{|c|}{$\begin{array}{l}\text { TABLA 4: Estadificación del CCM según la 7. e edición del AJCC, } 2010 . \\
\text { Adaptada de referencia } 38 .\end{array}$} \\
\hline
\end{tabular}




\begin{tabular}{|c|c|}
\hline $\mathbf{T}$ & Tumor primario \\
\hline Tx & No evaluable (p. ej., curetaje) \\
\hline T0 & No hay evidencia \\
\hline Tis & In situ \\
\hline T1 & Diámetro clínico máximo menor o igual a $2 \mathrm{~cm}$ \\
\hline $\mathrm{T} 2$ & $\begin{array}{l}\text { Diámetro clínico máximo mayor de } 2 \mathrm{~cm} \text { pero menor } 0 \\
\text { igual a } 5 \mathrm{~cm}\end{array}$ \\
\hline T3 & Diámetro clínico máximo mayor de $5 \mathrm{~cm}$ \\
\hline $\mathrm{T} 4$ & Invade fascia, músculo, cartílago o hueso \\
\hline $\mathbf{N}$ & Evaluación clínica de ganglios regionales \\
\hline $\mathrm{Nx}$ & $\begin{array}{l}\text { No evaluables (p. ej., linfadenectomía previa o cuestiones } \\
\text { anatómicas) }\end{array}$ \\
\hline NO & Sin evidencia clínica y/o radiológica de metástasis \\
\hline N1 & Metástasis en ganglio/s regional/es \\
\hline N2 & $\begin{array}{l}\text { Metástasis en tránsito, sin metástasis en ganglios regio- } \\
\text { nales }\end{array}$ \\
\hline N3 & Metástasis en tránsito, con metástasis en ganglios regionales \\
\hline $\mathbf{p N}$ & Evaluación histopatológica de ganglios regionales \\
\hline $\mathrm{pNx}$ & $\begin{array}{l}\text { No evaluables (p. ej., linfadenectomía previa o no fueron } \\
\text { remitidos) }\end{array}$ \\
\hline pNO & No se detectan metástasis \\
\hline pN1 & Presencia de metástasis \\
\hline $\begin{array}{l}\text { pN1a } \\
\text { (sn) }\end{array}$ & $\begin{array}{l}\text { Metástasis clínicamente oculta detectada por estudio del } \\
\text { ganglio centinela }\end{array}$ \\
\hline pN1a & Metástasis clínicamente oculta detectada por linfadenectomía \\
\hline $\mathrm{pN1b}$ & $\begin{array}{l}\text { Metástasis detectada clínica y/o radiológicamente confir- } \\
\text { mada por histopatología }\end{array}$ \\
\hline pN2 & Metástasis en tránsito, sin metástasis en ganglios regionales \\
\hline pN3 & Metástasis en tránsito, con metástasis en ganglios regionales \\
\hline M & Metástasis a distancia clínica y/o radiológica \\
\hline MO & No se detectan metástasis a distancia \\
\hline M1 & Detección de metástasis a distancia (clínica y/o imágenes) \\
\hline M1a & Piel, TCS o ganglio/s a distancia \\
\hline M1b & Pulmón \\
\hline M1c & Otros órganos \\
\hline pM & $\begin{array}{c}\text { Metástasis a distancia con confirmación } \\
\text { histopatológica }\end{array}$ \\
\hline MO & $\begin{array}{l}\text { No se detectan metástasis a distancia por evaluación } \\
\text { clínica y/o radiológica }\end{array}$ \\
\hline pM1 & Confirmación de metástasis a distancia \\
\hline pM1a & Piel, TCS o ganglio/s a distancia \\
\hline pM1b & Pulmón \\
\hline pM1c & Otros órganos \\
\hline
\end{tabular}

\begin{tabular}{|c|c|c|c|}
\hline \multicolumn{4}{|c|}{ Clínico (cTNM) } \\
\hline Estadio & $\mathbf{T}$ & N & M \\
\hline 0 & Tis & NO & $\mathrm{MC}$ \\
\hline 1 & $\mathrm{~T} 1$ & NO & $\mathrm{MC}$ \\
\hline$\| A$ & T2-T3 & NO & $\mathrm{MC}$ \\
\hline$\| B$ & T4 & NO & $\mathrm{MC}$ \\
\hline III & T0-T4 & N1-N3 & $\mathrm{MC}$ \\
\hline IV & T0-4 & Cualquier $\mathrm{N}$ & $M 1$ \\
\hline \multicolumn{4}{|c|}{ Histopatólogico (pTNM) } \\
\hline Estadio & $\mathbf{T}$ & $\mathbf{N}$ & M \\
\hline 0 & Tis & NO & MO \\
\hline I & $\mathrm{T} 1$ & NO & MO \\
\hline$\| A$ & $\mathrm{~T} 2-\mathrm{T} 3$ & NO & MO \\
\hline$\| B$ & T4 & NO & MO \\
\hline IIIA & $\begin{array}{l}\text { T1-T4 } \\
\text { T0 }\end{array}$ & $\begin{array}{l}\text { N1a(sn) } 0 \\
\text { N1a } \\
\text { N1b }\end{array}$ & $\begin{array}{l}\text { M0 } \\
\text { MO }\end{array}$ \\
\hline IIIB & T1-T4 & N1b-3 & MO \\
\hline IV & T0-4 & Cualquier $\mathrm{N}$ & M1 \\
\hline
\end{tabular}

TABLA 6: Estadificación del CCM según la 8. a edición del AJCC, 2018. Adaptada de referencia 37.

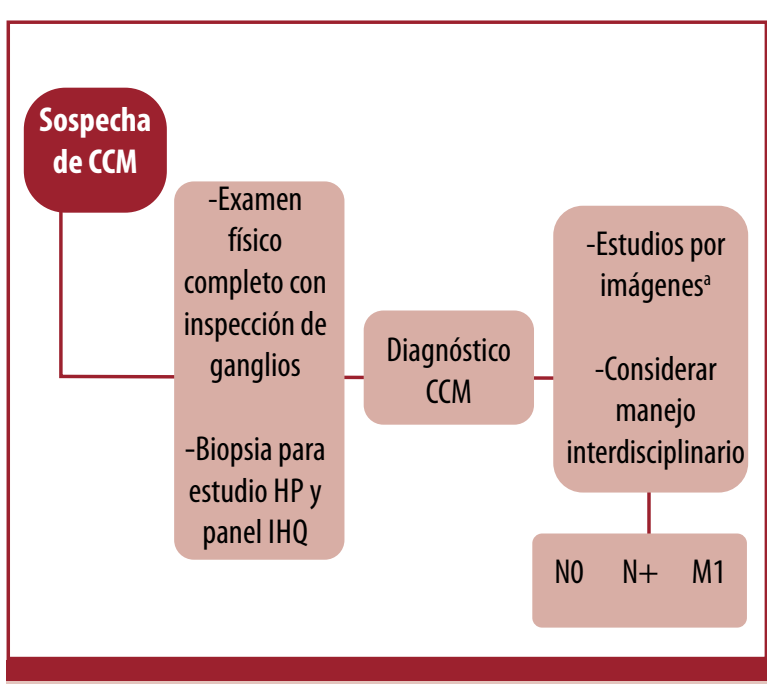

GRÁFICO 3: Algoritmo de manejo para el paciente con sospecha de CCM. a Se sugiere ante la sospecha de tumor irresecable o con probabilidad de metástasis de acuerdo con los hallazgos histopatológicos del tumor primario. 


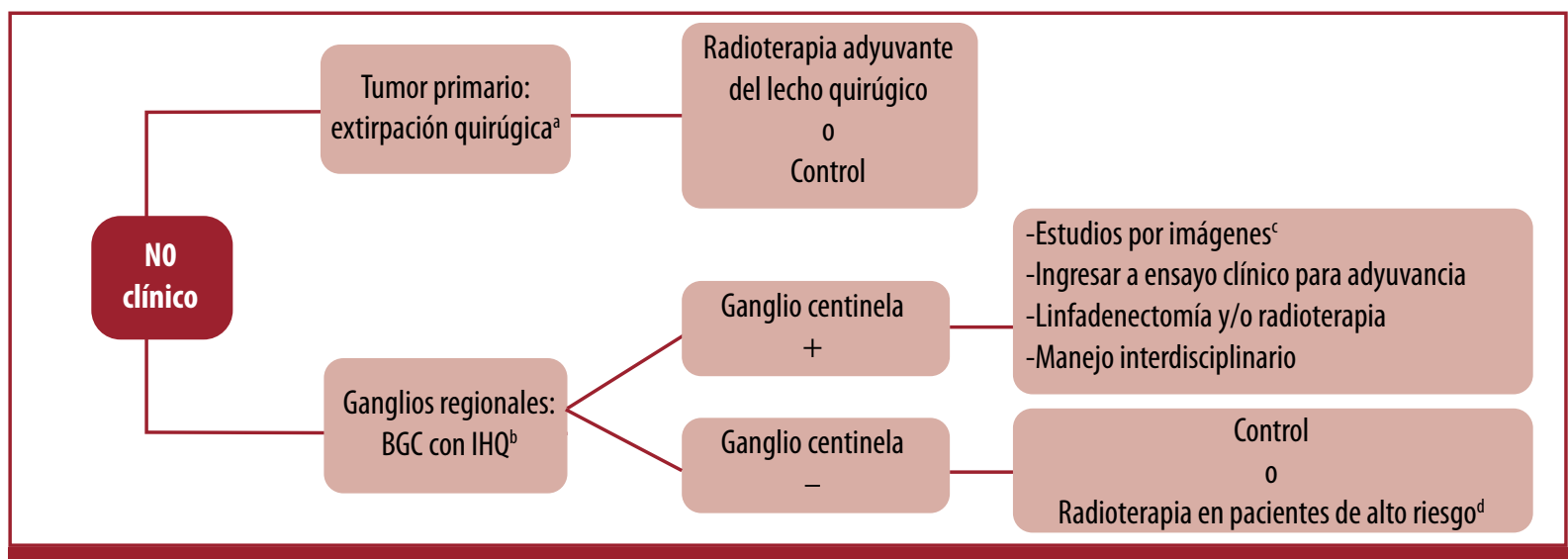

GRÁFICO 4: Algoritmo de manejo del tumor primario y ganglios regionales en el paciente N0 clínico.

aAnte contraindicación quirúrgica o en caso de negativa del paciente, la radioterapia como monoterapia podría considerarse como opción.

${ }^{\circ}$ En la cabeza y el cuello hay un alto riesgo de falso negativo debido a un drenaje linf́́tico aberrante o múltiple. De no realizar la BGC o de ser no exitosa, considerar la radioterapia ganglionar.

'En caso de no haber sido realizados previamente.

${ }^{\mathrm{I}}$ Inmunosuprimidos severos, por ejemplo, trasplantados de órgano sólido.

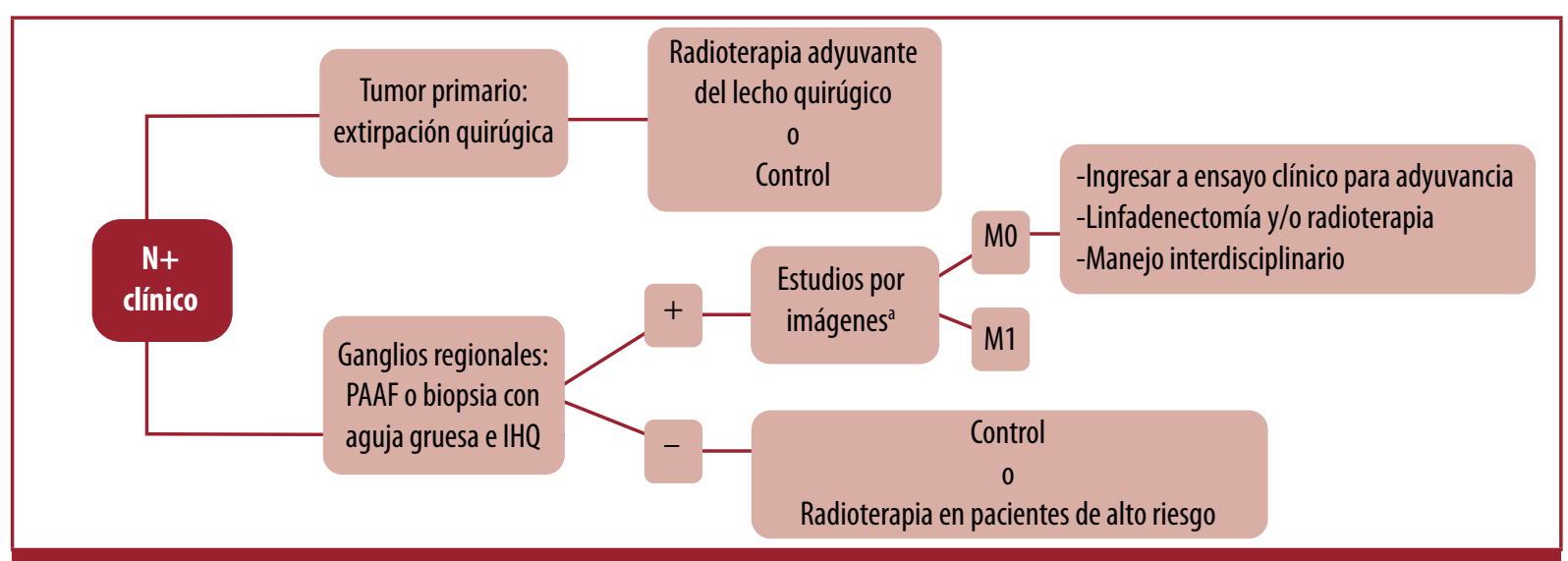

GRÁFICO 5: Algoritmo de manejo del paciente con adenopatías regionales clínicas, N+ clínico.

a En caso de no haber sido realizados previamente.

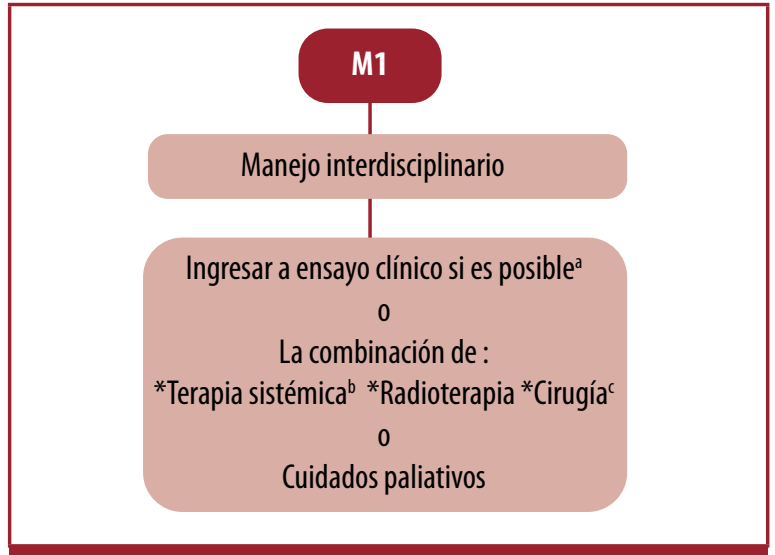

GRÁFICO 6: Algoritmo de manejo del paciente con metástasis a distancia. ${ }^{2} \mathrm{~N}$ o hay recomendaciones con respecto a un fármaco en particular; se destaca que a pesar de ser un tumor quimiosensible, la respuesta a la quimioterapia no es duradera.

${ }^{\mathrm{b}}$ Las terapias preferidas son los anti-PD-1/PD1L: avelumab, pembrolizumab y nivolumab, de acuerdo con los resultados preliminares de los últimos ensayos clínicos que muestran una mejor respuesta sostenida en el tiempo y un mejor perfil de seguridad con respecto a la quimioterapia citotóxica. ' Solo en casos seleccionados y con un abordaje interdisciplinario, considerar la extirpación de oligometástasis.

\section{EVOLUCIÓN Y PRONÓSTICO}

El CCM es una neoplasia maligna con altas tasas de mortalidad. Los números crecieron, además, en los últimos ańos como reflejo del aumento en la incidencia (un aumento del $360 \%$ en la incidencia, con un aumento del $333 \%$ en la tasa de mortalidad entre 1986 y 2011). La sobrevida a los 5 ańos es del $78 \%$ para la enfermedad local y localmente avanzada, del $54 \%$ con compromiso nodal regional y del $30 \%$ con enfermedad metastásica ${ }^{7}$.

Otros estudios muestran mayores porcentajes de mortalidad a los 5 años, 55\% para enfermedad local y $84 \%$ para no localizada, pero resaltan que debido al grupo etario en el que se presenta el CCM, hay un exceso de mortalidad atribuida a esta patología. Por otro lado, de 185 pacientes estudiados con CCM, 121 presentaron otra neoplasia asociada después del año del diagnóstico, el doble de incidencia con respecto a la población general ${ }^{8}$. 
Como ya se mencionó, las metástasis ganglionares regionales son un factor pronóstico determinante. Según Harms et ál., los pacientes con un ganglio centinela negativo tuvieron mayor sobrevida global a los 5 años $(62,8 \%)$ que aquellos sin adenopatías clínicas (45\%) y destacan la importancia del estudio histopatológico ganglionar ${ }^{42}$. Otros factores que tendrían un impacto negativo en la sobrevida son: edad mayor de 70 años, tener una segunda neoplasia asociada y los estados de inmunosupresión ${ }^{41}$.

Los sitios a los cuales metastatiza con mayor frecuencia son ganglios linfáticos a distancia, piel, hueso, médula ósea, pulmón, pleura e hígado. En segunda instancia puede diseminarse a páncreas, suprarrenales, cerebro y riñones ${ }^{37}$.

\section{TRATAMIENTO}

La conducta terapéutica se basa en el estadio. La extirpación quirúrgica del tumor primario con márgenes libres y radioterapia adyuvante del lecho es el tratamiento de elección en la enfermedad localizada. Dado que es más frecuente en la cara y el cuello, es importante contemplar la morbilidad que implican las resecciones amplias y entonces considerar las técnicas quirúrgicas que ahorran tejido (cirugía micrográfica de Mohs). Las guías recomiendan entre 1 a $2 \mathrm{~cm}$ de margen lateral y hasta la fascia o el periostio en el cráneo en profundidad $^{37,44,45}$. En un estudio con 240 pacientes se comparó la recurrencia locorregional y la sobrevida global tras la extirpación del tumor primario con $1 \mathrm{o}$ $2 \mathrm{~cm}$ de margen lateral de seguridad y con un seguimiento a 21 meses. Se concluyó que quienes recibieron $1 \mathrm{~cm}$ no presentaron mayor recurrencia local y la sobrevida global fue menor, aunque no significativa. Los autores destacaron que la mayoría de los pacientes a los que se le practicaron 2 o más centímetros de margen recibieron además radioterapia adyuvante ${ }^{46}$. Ante la imposibilidad de la extirpación quirúrgica del tumor (ya sea por contraindicación o negativa del paciente), la radioterapia como monoterapia es una alternativa dentro de un enfoque multidisciplinario ${ }^{37,45,47}$.

La radioterapia adyuvante del sitio quirúrgico del tumor primario mostró un aumento de la sobrevida global con respecto a la extirpación quirúrgica sola en los pacientes en estadios I y II. En contraposición, no hubo un aumento de la sobrevida en los pacientes con metástasis ganglionares regionales en las que se realizó linfadenectomía y radioterapia adyuvante ${ }^{48}$. En los pacientes inmunocompetentes con un tumor primario menor de $1 \mathrm{~cm}$, con resección amplia y sin invasión linfovascular, podría no realizarse la adyuvancia del lecho quirúrgico ${ }^{37,45}$.
Si se confirma la presencia de micrometástasis con el estudio del ganglio centinela, se recomienda en lo posible ingresar en un protocolo de ensayo clínico y la linfadenectomía radical y/o la radioterapia. Debido a la falta de estudios prospectivos y a la poca cantidad de estudios retrospectivos, no puede recomendarse un método u otro. Se sugiere la radioterapia adjuvante del lecho ganglionar ante el compromiso de múltiples ganglios o la rotura de la cápsula. En caso de no realizarse ganglio centinela o ante el riesgo de falsos negativos (p. ej., en la cabeza y el cuello), se propone considerar la realización de radioterapia en los ganglios regionales subclínicos ${ }^{37}$.

La quimioterapia fue hasta hace poco tiempo el tratamiento de elección para los pacientes con enfermedad avanzada. A pesar de ser un tumor quimiosensible, con los quimioterápicos convencionales la respuesta es corta y declina alrededor de los 9 meses. Los esquemas incluyen ciclofosfamida, doxorrubicina, vincristina, etopósido, cisplatino y carboplatino. Estos últimos se asocian particularmente a una elevada toxicidad ${ }^{49}$.

Tras el descubrimiento del MCPyV y la interrelación del tumor con la respuesta inmune del huésped tanto humoral como celular, se plantearon interrogantes respecto de la posibilidad de utilizar agentes biológicos como tratamiento. En el CCM, PD-L1 está expresado tanto por las células tumorales como por las células del infiltrado inflamatorio adyacente ${ }^{50}$. Su unión a la proteína PD-1 expresada por linfocitos T activados conduce a la inactivación de las vías de señalización responsables de la proliferación, supervivencia y actividad citotóxica de los linfocitos; de esta manera contribuye al escape inmunitario del tumor ${ }^{51}$.

$\mathrm{El}$ avelumab es un anticuerpo monoclonal humano IgG1 que no solo impide la unión PD-1/PD-L1, sino que además estimula la activación de linfocitos $\mathrm{T}$, la formación de anticuerpos y la citotoxicidad mediada por anticuerpos $^{49}$. En 2016, se publicaron los resultados del estudio JAVELIN 200 parte A, un ensayo clínico prospectivo en fase II con avelumab, un anticuerpo monoclonal anti PDL1 ligando, en 88 pacientes con CCM en estadio avanzado refractarios a la quimioterapia ${ }^{50}$. La respuesta fue del $31,8 \%$ y en el $82 \%$ de los casos se sostuvo con una media de seguimiento de 10,4 meses. El avelumab fue aprobado en 2017 por la FDA para los pacientes con CCM y metástasis a distancia con tratamientos previos o sin ellos. Tras un año de seguimiento, la tasa de respuesta se sostuvo, fue del $33 \%$ y la tasa de supervivencia, del $52 \%{ }^{52}$. En 2018, se publicó el resultado del JAVELIN parte B, que enroló a 39 pacientes con CCM estadio IV que nunca habían recibido terapia sistémica, con una tasa de respuesta del $62,1 \%$, una media de seguimiento de 5,1 meses y una supervivencia sin progresión de 9,1 meses $^{53}$. 
El pembrolizumab y el nivolumab son anticuerpos monoclonales anti-PD-1 y también fueron estudiados para evaluar su respuesta a largo plazo ${ }^{38,44}$. En 2016, Nghiem et ál. publicaron los resultados de un estudio multicéntrico, no controlado, en fase II, de 26 pacientes con CCM avanzado que nunca recibieron tratamiento, tratados con pembrolizumab, con una respuesta del $56 \%$ (16\% de respuesta total y $40 \%$ de respuesta parcial). La media de seguimiento fue de 33 semanas, la duración de la respuesta fue variable (entre 2,2 y 9,7 meses) y la SLP a los 6 meses fue del $67 \%{ }^{54}$. A partir de estos resultados, el pembrolizumab fue aprobado por la FDA a fines de 2018. A principios de 2019, el mismo autor y sus colaboradores publicaron los resultados del KEYNOTE-017, el estudio con mayor tiempo de observación hasta la fecha (2 años) para el pembrolizumab, con un total de 50 pacientes con CCM avanzado sin tratamiento sistémico previo, con una tasa objetiva de respuesta del 56\% (24\% respuesta completa y $32 \%$ parcial). En ambos la respuesta al pembrolizumab en los tumores MCPyV positivos y negativos fue similar ${ }^{54,55}$.

Con esta evidencia, desde 2018 el avelumab, el pembrolizumab y el nivolumab se convirtieron en el tratamiento de primera línea para los pacientes con CCM estadio IV según las guías terapéuticas y es de elección el ingreso de estos enfermos en ensayos clínicos para continuar el estudio prospectivo de esos fármacos ${ }^{38}$.

\section{CONCLUSIONES}

La tasa de incidencia del CCM aumentó significativamente en los últimos años y se espera que conti-

\section{BIBLIOGRAFÍA}

1. Toker C. Trabecular carcinoma of the skin. Arch Dermatol 1972;105:107-110.

2. Tang CK, Toker C. Trabecular carcinoma of the skin. An ultrastructural study. Cancer 1978;42:2311-2321.

3. Paulson KG, Park SY, Vandeven NA, Lachance K, et ál. Merkel cell carcinoma: Current US incidence and projected increases based on changing demographics. J Am Acad Dermatol 2018;78:457-463.

4. Schadendorf D, Lebbé C, Hausen A, Avril MF, et ál. Merkel cell carcinoma: Epidemiology, prognosis, therapy and unmet medical needs. Eur J Cancer 2017;71:53-69.

5. Hodgson NC. Merkel cell carcinoma: Changing incidence trends.J Surg Oncol 2005;89:1-4.

6. Youlden DR, Soyer HP, Youl PH, Fritschi L, et ál. Incidence and survival for merkel cell carcinoma in Queensland, Australia, 19932010. JAm Acad Dermatol 2014;150:864-872.

7. Fitzgerald TL, Dennis S, Kachare SD, Vohra NA, et ál. Dramatic increase in the incidence and mortality from merkel cell carcinoma in the United States. Am Surg 2015;81:802-806.

8. Kaae J, Hansen AV, Biggar RJ, Boyd HA, et ál. Merkel cell carcinoma: Incidence, mortality, and risk of other cancers. J Natl Cancer Inst 2010;102:793-801. núe en ascenso. Si bien este aumento es multifactorial, debido a que se observó la misma tendencia en otras neoplasias cutáneas relacionadas con la exposición a la RUV, es fundamentamental el rol del dermatólogo en la fotoeducación, en brindar la información y en enfatizar sobre la importancia de la realización de controles clínicos anuales.

Dado que se trata de una entidad con baja sospecha clínica que muchas veces es confundida con lesiones benignas o malignas más frecuentes, resulta de utilidad recordar el acrónimo AEIOU, que destaca las principales características clínicas, como el rápido crecimiento y la falta de síntomas, y las características epidemiológicas claves. Ante la sospecha de CCM, sería valioso aprovechar la oportunidad para estudiar los estados de inmunodeficiencia.

El diagnóstico temprano es de suma importancia, ya que el factor pronóstico más determinante es el compromiso ganglionar regional. Por este motivo, en las últimas guías se incorporó la recomendación de realizar la biopsia del ganglio centinela siempre que sea posible. Es necesario un enfoque multidisciplinario para abordar el tratamiento de los pacientes a partir del estadio III.

Por último, una de las grandes limitaciones para el estudio de esta enfermedad es su poca frecuencia, así como la falta de estudios prospectivos. En los últimos años, se realizaron estudios prospectivos para evaluar la eficacia de las terapias inmunomoduladoras en el tratamiento de los pacientes en estadio IV. Si bien hasta ahora los resultados son prometedores para este grupo de enfermos, el pronóstico es aún desfavorable.

9. Lemos B, Nghiem P. Merkel cell carcinoma: More deaths but still no pathway to blame. J Invest Dermatol 2007;127:2100-2103.

10. Girschik J, Thorn K, Beer TW, Heenan PJ, et ál. Merkel cell carcinoma in Western Australia: A population-based study of incidence and survival. Br J Dermatol 2011;165:1051-1057.

11. Zaar $\mathrm{O}$, Gillstedt $M$, Lindelöf $B$, Wennberg-Larkö AM, et ál. Merkel cell carcinoma incidence is increasing in Sweden. J Eur Acad Dermatol Venereol 2016;30:1708-1713.

12. Fondain $M, D u$ Thanh $A$, Bessaoud $F$, Dereure $O$, et ál. Epidemiological trends in Merkel cell carcinoma in southern France: a registry-based study. Br JDermatol 2017;176:1379-1381.

13. Eisemann N, Waldmann A, Geller AC, Weinstock MA, et ál. Nonmelanoma skin cancer incidence and impact of skin cancer screening on incidence. J Invest Dermatol 2014;134:43-50.

14. Reichgelt BA, Visser O. Epidemiology and survival of Merkel cell carcinoma in the Netherlands. A population-based study of 808 cases in 1993-2007. Eur J Cancer 2011;47:579-585.

15. Heath $M$, Jaimes $N$, Lemos B, Mostaghimi $A$, et ál. Clinical characteristics of Merkel cell carcinoma at diagnosis in 195 patients: the AEIOU features. J Am Acad Dermatol 2008;58:375-381.

16. Wong SQ, Waldeck K, Vergara I, Schröder J, et ál. UV-associated 
mutations underlie the etiology of MCV-negative Merkel cell carcinomas. Cancer Res 2015;75:5228-5234.

17. Wang TS, Byrne PJ, Jacobs LK, Taube JM. Merkel Cell Carcinoma: Update and Review. Semin Cutan Med Surg 2011;30:48-56.

18. Walsh NMG. Primary neuroendocrine (Merkel cell) carcinoma of the skin: Morphologic diversity and implications thereof. Hum Pathol 2001;32:680-689.

19. Lunder EJ, Stern RS. Merkel cell carcinoma in patients treated with methoxsalen and ultraviolet $\mathrm{A}$ radiation. $N$ Engl $\mathrm{J}$ Med 1998;339:1247-1248.

20. Lanoy E, Costagliola D, Engels EA. Skin cancers associated with HIV infection and solid-organ transplantation among elderly adults. Int J Cancer 2010;126:1724-1731.

21. Feng $H$, Shuda $M$, Chang $Y$, Moore PS. Clonal integration of a polyomavirus in human Merkel cell carcinoma. Science 2008;319:1096-1100.

22. Chang Y, Moore PS. Merkel cell carcinoma: a virus-induced human cancer. Annu Rev Pathol 2012;7:123-144.

23. Samimi $M$, Touzé A. Merkel cell carcinoma: The first human cancer shown to be associated with a polyomavirus. Presse Med 2014;43:e405-e411.

24. Harms PW, Vats $\mathrm{P}$, Verhaegen $\mathrm{ME}$, Robinson $\mathrm{DR}$, et ál. The distinctive mutational spectra of polyomavirus-negative merkel cell carcinoma. Cancer Res 2015;75:3720-3727.

25. Saadi ME, Alarcón B, Abeldaño A, Brea P, et ál. Carcinoma de células de Merkel. Dermatol Argent 2002;8:218-222.

26. Viola A, Martinez M, Larre Borges A, Laporte M, et ál. Carcinoma de células de Merkel. Med Cutan Iber Lat Am 2008;36:142-145.

27. Paradela S, Peña C, Fernández-Jorge B, Vieira V, et ál. Carcinoma de células de Merkel. Actas Dermosifiliogr 2004;95:553-559.

28. Cañadas NG, Luna PC, Nocito MJ, Lustia MM, et ál. Carcinoma de células de Merkel. Estudio de 5 casos. Dermatol Argent 2009;15:428-433.

29. Radonich JE, Sanz A, Montardit AL, Sanz P, et ál. Carcinoma de células de Merkel asociado a linfoma B folicular. Arch Argent Dermatol 2016;66:45-48.

30. Cohen Sabban E, Lacassagne J, Pietrapaolo N, Mohr Y, et ál. Carcinoma de células de Merkel estadio III. Arch Argent Dermatol 2007;57:95-101.

31. Calder KB, Smoller BR. New insights into merkel cell carcinoma. Adv Anat Pathol 2010;17:155-161.

32. Cappetta ME, Casas G, Stengel F. Tumor de células de Merkel. Revisión de la literatura. Arch Argent Dermatol 2009;59:227-238.

33. McCalmont TH. Paranuclear dots of neurofilament reliably identify Merkel cell carcinoma. J Cutan Pathol 2010;37:821-823.

34. Smoller BR, Bichakjian C, Brown A, Crowson AN, et ál. Protocol for the Examination of Specimens From Patients With Merkel Cell Carcinoma of the Skin.[en línea] College of American Pathologists, junio 2017. Version: MerkelCell 4.0.0.1 <https://documents. cap.org/protocols/cp-skin-merkelcell-17protocol-4001.pdf [Consultado octubre 2018].

35. Gupta SG, Wang LC, Peñas PF, Gellenthin M, et ál. Sentinel Lymph Node Biopsy for Evaluation and Treatment of Patients With Merkel Cell Carcinoma. Arch Dermatol 2006;142:685-690.

36. Colgan MB, Tarantola TI, Weaver AL, Wiseman G, et ál. The predictive value of imaging studies in evaluating regional lymph node involvement in Merkel cell carcinoma. J Am Acad Dermatol 2012;67:1250-1256.

37. Merkel cell carcinoma NCCN clinical Practice guidelines in Oncology. Versión 2.2019<https://merkelcell.org/wpcontent/ uploads/2019/01/MCC_v.2.2019.pdf. [Consulta: agosto 2019].
38. Edge SB, Byrd DR, Compton CC, Fritz AG, etál.Merkel cell carcinoma. AJCC Cancer Staging Manual. $7^{\text {th }}$ ed. Springer; 2010;315-323.

39. Lemos BD, Storer BE, lyer JG, Phillips JL, et ál. Pathologic nodal evaluation improves prognostic accuracy in Merkel cell carcinoma: Analysis of 5823 cases as the basis of the first consensus staging system. J Am Acad Dermatol 2010;63:751-761.

40. Sadeghi R, Adinehpoor Z, Maleki M, Fallahi B, et ál. Prognostic Significance of Sentinel Lymph Node Mapping in Merkel Cell Carcinoma: Systematic Review and Meta-Analysis of Prognostic Studies. Biomed Res Int 2014;2014:489536.

41. Tarantola TI, Vallow LA, Halyard MY, Weenig RH, et ál. Prognostic factors in Merkel cell carcinoma: Analysis of 240 cases. J Am Acad Dermatol 2013;68:425-432.

42. Harms KL, Healy MA, Nghiem P, Sober AJ, et ál. Analysis of prognostic factors from 9387 Merkel Cell Carcinoma Cases Forms the Basis for the New 8th Edition AJCC Staging System. Ann Surg Oncol 2016;23:3564-3571.

43. Cornejo C, Miller CJ. Merkel Cell Carcinoma: Updates on Staging and Management. Dermatol Clin 2019;37:269-277.

44. Tello TL, Coggshall K, Yom SS, Yu SS. Merkel cell carcinoma: An update and review: Current and future therapy. J Am Acad Dermatol 2018;78:445-454.

45. Lebbe C, Becker JC, Grob JJ, Mallvehy J, et ál. Diagnosis and treatment of Merkel Cell Carcinoma. European consensusbased interdisciplinary guideline. Eur J Cancer 2015;51:23962403.

46. Perez MC, Pinho FR, Holstein A, Oliver DE, et ál. Resection Margins in Merkel Cell Carcinoma: Is a $1-\mathrm{cm}$ Margin Wide Enough ? Ann Surg Oncol 2018;25:3334-3340.

47. Patel P, Modi C, McClellan B, Ohri N. Radiotherapy for inoperable Merkel cell carcinoma: a systematic review and pooled analysis. Dermatol Pract Concept 2018;8:149-157.

48. Bhatia S, Storer BE, lyer JG, Moshiri A, et ál. Adjuvant Radiation Therapy and Chemotherapy in Merkel Cell Carcinoma: Survival Analyses of 6908 Cases from the National Cancer Data Base. J Natl Cancer Inst 2016;108: djww042.

49. Femia D, Prinzi N, Anichini A, Mortarini R, et ál. Treatment of Advanced Merkel Cell Carcinoma: Current Therapeutic Options and Novel Immunotherapy Approaches. Target Oncol 2018;13:567-582.

50. Kaufman HL, Russell J, Hamid O, Bhatia S, et ál. Avelumab in patients with chemotherapy-refractory metastatic Merkel cell carcinoma: a multicentre, single-group, open-label, phase 2 trial. Lancet Oncol 2016;17:1374-1385.

51. Zitvogel L, Kroemer G. Targeting PD-1/PD-1L interactions for cancer immunotherapy. Oncoimmunology 2012;1:1223-1225.

52. Kaufman HL, Russell J, Hamid O, Bhatia S, et ál. Updated efficacy of avelumab in patients with previously treated metastatic Merkel cell carcinoma after $\geq 1$ year of follow-up: JAVELIN Merkel 200, a phase 2 clinical trial. J Immunother Cancer 2018;6:7.

53. D’Angelo SP, Russell J, Lebbé C, Chmielowski B, et ál. Efficacy and safety of first-line avelumab treatment in patients with stage IV metastatic merkel cell carcinoma a preplanned interim analysis of a clinical trial. JAMA Oncol 2018;4:e180077.

54. Nghiem PT, Bhatia S, Lipson EJ, Kudchadkar RR, et ál. PD-1 blockade with pembrolizumab in advanced merkel-cell carcinoma. N Engl J Med 2016;374:2542-2552.

55. Nghiem PT, Bhatia S, Lipson EJ, Sharfman WH, et ál. Durable tumor regression and overall survival in patients with advanced Merkel cell carcinoma receiving pembrolizumab as first-line therapy. J Clin Oncol 2019;37:693-702. 
1) Son factores de riesgo para CCM:

A- Inmunosupresión severa.

B- Historia de fotoexposición.

C-Edad avanzada.

D- Todas las opciones son correctas.

2) La media de edad en el momento del diagnóstico es:

A- Entre 60 y 69 años.

B- Entre 70 y 75 años.

C - Entre 70 y 79 años.

D- Entre 80 y 85 años.

3) Con respecto a la etiopatogenia del CCM:

A- Acorde con lo publicado los tumores MCPyV-negativos son más frecuentes que los MCPyV-positivos.

B- Los tumores MCPyV-negativos presentan mayor fracción de citidina sobre timina y abundantes dímeros de pirimidinas.

C- Los tumores MCPyV positivos en general no presentan un infiltrado inflamatorio abundante.

D- El potencial oncogénico viral estaría relacionado con genes de transcripción tardía, como large T antigen (LTag) y small T antigen (sT).

4) El acrónimo AEIOU hace mención a las siguientes características, excepto:

A- Lesión eritematosa 0 eritematoviolácea firme.

B- Lesión de rápido crecimiento.

C- Lesión asintomática.

D- Inmunodepresión presente.

5) En la histopatología, con tinción de hematoxilina y eosina se presenta como:

A- Tumor compuesto por células basófilas pequeñas y monomorfas en la dermis y la epidermis.

B- Tumor dérmico compuesto por células basófilas pequeñas, monomorfas, de escaso citoplasma, con núcleos hipercromáticos y cromatina finamente granular.

C- Tumor compuesto por células basófilas grandes de escaso citoplasma, en la dermis y la hipodermis.

D- La presencia de figuras mitóticas y apoptóticas es un hallazgo infrecuente.

6) Señale cuáles de los siguientes marcadores IHQ no son frecuentes en el CCM:

A-TTF-1.

B- CK-20.

C-Enolasa neuroespecífica.

D- Cromogranina A.
7) Los siguientes son considerados factores pronósticos negativos con respecto a la sobrevida, excepto:

A- Inmunosupresión.

B- Antecedentes de neoplasias cutáneas previas.

C- Presencia de una segunda neoplasia asociada.

D- Metástasis ganglionar regional.

8) Un paciente de 69 años, con antecedentes de leucemia linfocítica crónica, presenta una lesión tumoral de $1 \mathrm{~cm}$ en el brazo derecho con adenopatías axilares homolaterales, con diagnóstico histopatológico de CCM, ¿cuál es la conducta?

A- Extirpación del tumor primario con márgenes de 1 a $2 \mathrm{~cm}$ laterales hasta la fascia, con radioterapia adyuvante 0 sin ella, y estudios por imágenes para descartar metástasis.

B- Extirpación del tumor primario con márgenes de 1 a $2 \mathrm{~cm}$ laterales hasta el periostio, radioterapia adyuvante del lecho y estudios por imágenes para descartar metástasis.

C- Solicitar estudios por imágenes para descartar metástasis a distancia; si son negativos, extirpación del tumor primario con márgenes de 1 a $2 \mathrm{~cm}$ laterales hasta la fascia, con radioterapia adyuvante 0 sin ella, y biopsia del ganglio centinela.

D- Solicitar estudios por imágenes para descartar metástasis a distancia; si son negativos, extirpación del tumor primario con márgenes de 1 a $2 \mathrm{~cm}$ laterales hasta la fascia, con radioterapia adyuvante 0 sin ella, y biopsia de ganglio axilar.

9) Las metástasis son más frecuentes en:
A- Piel.
B-Pulmón.
C- Ganglios linfáticos distantes.
D- Médula ósea.

10) Con respecto a los posibles tratamientos de los pacientes en estadios III y IV:

A-El avelumab es un anticuerpo monoclonal que impide la unión PD-1/PD-L1 y estimula la activación de linfocitos T, la formación de anticuerpos y la citotoxicidad mediada por anticuerpos.

B-El pembrolizumab es un anti-PD-1 aprobado en 2018 para los pacientes en estadio IV.

C- El avelumab fue aprobado en 2017 para el tratamiento de los pacientes en estadio IV.

D- Todas las opciones son correctas.
Respuestas correctas Vol. XXVI, № 3, 2020

1. B/2.C/3.A/4.A/5. D/6.B/7. B/8.C/9.C/10. C 